\title{
The Exploration of Factors That Affect Travel Safety of Child Passengers
}

\author{
Kai Liu \\ School of Automotive Engineering, Shanghai University of Engineering Science, Shanghai, China \\ Email:1065790643@qq.com
}

How to cite this paper: Liu, K. (2018) The Exploration of Factors That Affect Travel Safety of Child Passengers. Open Access Library Journal, 5: e4574. https://doi.org/10.4236/oalib.1104574

Received: April 5, 2018

Accepted: April 25, 2018

Published: April 28, 2018

Copyright (c) 2018 by author and Open Access Library Inc.

This work is licensed under the Creative Commons Attribution International License (CC BY 4.0).

http://creativecommons.org/licenses/by/4.0/

\section{Open Access}

\begin{abstract}
There are few studies on the travel safety of child passenger in China. The study aims to describe the seating position and restraint practice of child passenger in China's first-tier cities. The travel information on the children enrolled in 10 early education institutions, 15 kindergartens and 10 primary schools was randomly selected in Beijing, Shanghai, Guangzhou, Chongqing and Jinan in recent years. A total of 4900 parents were surveyed to collect children's travel information and 3556 valid questionnaires were taken back. The adjusted rate ratios for optimal seating position (rear-seated alone) versus suboptimal seating position and restraint use versus non-use of restraints among child passengers were analyzed and evaluated using multivariate binomial regression. Through the survey, it is found that the suboptimal seating position (31.2\%) and non-use of restraints (45.4\%) were common among child passengers. Younger age ( $\leq 8$ years old) is an unfavorable factor resulting in seating in rear seats by child passengers; and the higher the driver's degree of education, the higher the family income and the more understanding about car seat is, the bigger likelihood of being rear-seated alone by child passengers is. Younger age ( $\leq 8$ years old) is also an unfavorable factor resulting in restraint use by child passengers; and the more understanding about car seat, the more concern on the relevant legislative information and the more knowledge about defective car seat recall have by parents, the bigger likelihood of using restraints for their children during travel. This study suggests that restraint non-use and suboptimal seating position are still common among child passengers in China's first-tier cities and also identifies the factors influencing restraint use and seating position choice for child passengers. There is an urgent need to improve child passenger safety in China. At the same time, it is also necessary to strengthen the publicity about child passenger's safety before the relevant laws and regulations are promulgated.
\end{abstract}

\section{Subject Areas}

Global Health, Health Policy 


\section{Keywords}

Child Passengers, Restraints, Seating Position, Questionnaire Survey, Travel Safety

\section{Introduction}

Travel safety of children is a current social hot spot in China. In 2010, traffic accident caused 2690 children ( 1 - 15 years) died and 14,733 children injured in China, with the number of child death accounted for $39.3 \%$ of the total number of deaths in the current population statistics [1]. In 2012, there were still 2572 children died and 9581 children injured in road accident [2]. The fatality rate among children in China is much higher than other developed countries [3]. Each year, about 100,000 people in China died in motor vehicle crashes, and children aged $1-20$ years accounted for more than $12 \%$ of these deaths [4]. Traffic accidents have become a leading cause of child death in China.

The vast majority of child passenger injuries are preventable. The study shows that rear seating and restraint use for child passengers can effectively reduce injury risks in crashes [5]. In China, the current laws and regulations on the compulsory use of child restraints and the public safety seminars for promoting child travel safety are very short [6]. Local laws and regulations on the compulsory use of child restraints are introduced only in few cities, such as Shanghai, Shandong, Shenzhen and Nanjing etc. Despite China's Road Traffic Safety Regulation went into effect in 2004 and mandated that drivers and front seat passengers must wear seatbelts, the seat-belt use rate was still very low, ranging from $23 \%$ to $67 \%$ for drivers and $1 \%$ to $50 \%$ for front seat passengers [7]. So it is not surprising that many child passengers are unrestrained or are seated in the front seat. Routley et al. [8] observed the use of seat belt in two major cities in eastern China (Nanjing and Zhoushan) and among the subset of child passengers aged $0-8$ years, they reported that $98 \%$ of passengers were unrestrained, none used child restraints and approximately $20 \%$ of child passengers were front seated during the travel. A parental investigation report conducted in a Beijing shopping mall found that $64.8 \%$ of the children aged 0 - 14 years used some restraint and $31.1 \%$ of children were front seated [9]. The investigation results conducted by Shuming Pan et al. [10] in Songjiang and Pudong districts of Shanghai showed that $60.8 \%$ of the children aged $0-7$ years were unrestrained and $16.9 \%$ of children were seated in suboptimal seat during the travel. Xiaojun Chen et al. [11] observed and investigated the child passenger seating position and restraint use in a second-tier city-Shantou. They found that $57.8 \%$ of children were rear seated and only $7.1 \%$ of children used restraint in proper manner.

Prioritizing appropriate countermeasures to reduce child passenger casualties in road accidents (such as increasing child restraint use and rear seating) requires an understanding about the social context, especially parents whose 
cognition will determine how children travel in car. Compared with other developed countries, China's concern on child passenger safety practice is still quite missing. This paper aimed to fully describe child passenger safety practices in China's first-tier cities and obtain the information about parental attributes influence on child passengers' seating position and restraint use through questionnaire study on child passenger safety practice in five cities including Beijing, Shanghai, Guangzhou, Chongqing and Jinan.

\section{Methods}

\subsection{Survey Method}

During the period from May 2014 to May 2015, a total of 4900 parents were subject to the questionnaire survey conducted in 10 early education institutions, 15 kindergartens and 10 primary schools randomly selected in Beijing, Shanghai, Guangzhou, Chongqing and Jinan. A unified questionnaire was used in the survey. All questionnaires were delivered to all children who took home the questionnaires and transferred to their parents. The completed questionnaires were returned in the second day. Research experts participated in the entire survey process, where they were responsible for questionnaire design, discussion and data analysis.

\subsection{Survey Questionnaire}

The questionnaire consists of two parts: basic information and restraint type. Basic information includes child' age (year), gender, relationship with driver, driver's education, family income(RMB/year), understanding about car seat, concern on legislation of car seat and understanding about recall of defective car seat; Restraint type includes restraint used, type of restraint used and seating position.

\subsection{Data Statistics and Analysis}

For data analysis, two outcomes were selected as the dependent variables in this paper: seating position and restraint use by child passengers. The classification was done in a binary way, that is, seating position as optimal (rear seated other than on an adult lap) and suboptimal (including always front seated, sitting on an adult's lap and others); restraint use as any restraint use (including car seat, booster and seat belt) and no restraint use; each child's age as either $\leq 8$ years (preschool age) and $>9$ years (school age); gender as male and female; relationship between driver and children as parent and non-parent; driver education level as college or above and college or lower; family income as high ( $>\mathrm{RMB}$ 100,000 a year) and low ( $<$ RMB 100,000 a year); understanding about car seat as yes and no; concern on legislative information about car seat as yes and no; and understanding about car seat recall as yes and no.

This paper describes the use and form of restraints (such as car seat, adult seat belt) as well as seating position of the children in different age groups and dif- 
ferent cities through descriptive statistics. The binary logistic regression analysis was used to evaluate the factors that affect restraint use and the rear seating position. All data analyses were completed using SPASS 17.0. The degree of influence on the dependent variables caused by independent variables was analyzed mainly by using the adjusted rate ratios (RR).

\section{Results}

\subsection{Statistic Analysis}

A total of 4900 questionnaires were handed out and 3556 valid questionnaires were returned in this survey, with an effective questionnaire rate of $72.6 \%$. As shown in Table 1, the surveyed children aged 1 - 15 years included 1712 boys and 1844 girls. Of 3556 children observed in this survey, 54.7\% used restraint, where $20.9 \%$ were in car seat; $68.8 \%$ was rear seated. For the infants aged 0 - 3 years and preschool children, of 2391 children observed in this survey, 1106 children were not placed in restraints, with the proportion $46.3 \%$. For the school children aged 9 - 15 years, $51.0 \%$ were wearing adult seat belt. For the infants aged 0 - 3 years, 205 infants were sitting in an adult's lap, accounting for $36.1 \%$. For all the children observed in this survey, about 5.6\% were placed in the front passenger seat. On the whole, child restraint use is less affected by age. The younger the child is, the high use rate of car seat is. As the age increased, the use rate of seat belt started to increase. In this survey, it found that only $363(10.2 \%)$ children were sitting in the car seat on rear seat.

Table 1. Restraint use and seating positions of child passengers traveling in a car in china's first-tier cities, 2014-2015, n (\%).

\begin{tabular}{|c|c|c|c|c|}
\hline & \multicolumn{3}{|c|}{ Age group } & Total \\
\hline & Ages $0-3$ & Ages $4-8$ & Ages $9-15$ & \multirow[b]{2}{*}{$\mathrm{N} /(\%)$} \\
\hline & $\begin{array}{l}\text { Primarily infants } \\
\text { and toddlers }\end{array}$ & Preschool children & School children & \\
\hline Total (N) & 568 & 1823 & 1165 & 3556 \\
\hline \multicolumn{5}{|l|}{ Restraint used } \\
\hline Yes & $319(56.2)$ & $966(53.0)$ & $660(56.7)$ & $1945(54.7)$ \\
\hline No & $249(43.8)$ & $857(47.0)$ & $505(43.3)$ & $1611(45.3)$ \\
\hline \multicolumn{5}{|c|}{$\begin{array}{c}\text { Type of restraint } \\
\text { used }\end{array}$} \\
\hline Car seat & $253(44.5)$ & $386(21.2)$ & $104(8.9)$ & 743 (20.9) \\
\hline Seatbelt & $97(17.1)$ & $658(36.1)$ & $594(51.0)$ & 1349 (37.9) \\
\hline Both & 31 & 78 & 38 & \\
\hline \multicolumn{5}{|c|}{ Seating position ${ }^{\mathrm{a}}$} \\
\hline Front seated & $40(7.0)$ & $77(4.2)$ & $83(7.1)$ & $200(5.6)$ \\
\hline Rear seated & $216(38.0)$ & $1299(71.3)$ & $933(80.1)$ & $2448(68.8)$ \\
\hline Adult's lap & $205(36.1)$ & $144(7.9)$ & $9(0.8)$ & $358(10.1)$ \\
\hline Others & $15(2.6)$ & 267 (14.6) & $125(10.7)$ & 407 (11.4) \\
\hline
\end{tabular}

${ }^{\mathrm{a}}$ Less than the total because of missing value. 
Five cities in China were involved in this survey: Beijing, Shanghai, Guangzhou, Chongqing and Jinan. As shown in Table 2. The restraint use rate of child passenger was basically same in these five cities, between $52 \%$ and 57\%. Especially, the highest use rate of car seat was in Shanghai, where a total of 183 (24.6\%) among 743 children observed preferred to use car seat; the lowest use rate of car seat was in Beijing, among 632 children observed only 105 (16.6\%) were willing to use car seat. 731 children were surveyed in Jinan, where 547 children were sitting in the rear seats, with a relatively highest proportion of $74.8 \%$, while a total of 472 among 729 children observed were rear seated in Chongqing, with a relative lowest proportion of $64.7 \%$. For the number of children sitting in car seat on rear seat and the corresponding proportion in these five cities, as shown in Figure 1, where the highest proportion of $15.10 \%$ in Shanghai and the relatively lowest proportion in Guangzhou, only $6.1 \%$.

3427 respondents $(96.4 \%)$ were parents, while the rest were relatives or hired professional drivers. $6.7 \%$ of the respondents $(n=238)$ reported that they had never heard of car seat; $72.8 \%$ of the respondents $(n=2,589)$ stated that they had heard of it but knew little; $20.5 \%$ of the respondents $(n=20.5 \%)$ reported that they used car seat and had a full understanding about it. About $80 \%$ of the respondents thought that it was necessary to have child in a car seat during the travel.

\subsection{Binary Logistic Regression Analysis}

When it came to the reason for not using car seat, $8.4 \%$ of the parents were lacking of awareness; $39.7 \%$ of the parents did not care about the legislation on car seat and $59.7 \%$ of the parents considered the price of car seat on the market were too high. As shown in Table 3, the more understanding about car seat $(\mathrm{RR}=4.749,95 \% \mathrm{CI}=3.879,5.813)$, the more concern on legislation information about car seat $(\mathrm{RR}=1.400,95 \% \mathrm{CI}=1.206,1.625)$ and more understanding about recall of defective car seat $(\mathrm{RR}=1.279,95 \% \mathrm{CI}=1.065,1.536)$ are favorable factors for children to be restrained during the travel; while younger age $(\mathrm{RR}=0.715,95 \% \mathrm{CI}=0.616,0.831)$ is an unfavorable factor resulting in restrained. Drivers with higher education level $(\mathrm{RR}=1.318,95 \% \mathrm{CI}=1.126$, $1.544)$, high family income $(\mathrm{RR}=1.272,95 \% \mathrm{CI}=1.091,1.483)$ and deep understanding about car seat $(\mathrm{RR}=1.993,95 \% \mathrm{CI}=1.633,2.434)$ are favorable for having children rear seated, while younger children $(\mathrm{RR}=0.349,95 \% \mathrm{CI}=$ $0.294,0.415$ ) are unfavorable.

\section{Discussion}

This study demonstrates that the child's age, driver's education level, family income and degree of understanding about car seat were associated with how children in China are seated, while the child's age, degree of understanding about car seat, concern on legislative information about car seat and the degree of understanding about recall of defective car seat were associated with whether children use restraints in cars. The results highlight the urgent need for improving 
Table 2. Restraint use and seating positions of child passengers traveling in a car in different cities, 2014-2015, n (\%).

\begin{tabular}{cccccc}
\hline & \multicolumn{5}{c}{ City } \\
\cline { 2 - 6 } & Beijing & Shanghai & Guangzhou & Chongqing & Jinan \\
\hline Total (N) & 632 & 743 & 721 & 729 & 731 \\
Restraint used & & & & & \\
Yes & $333(52.7)$ & $414(55.7)$ & $381(52.8)$ & $413(56.7)$ & $404(55.3)$ \\
No & $299(47.3)$ & $329(44.3)$ & $340(47.2)$ & $316(43.3)$ & $327(44.7)$ \\
Type of restraint used & & & & & \\
Car seat & $105(16.6)$ & $183(24.6)$ & $137(19.0)$ & $162(22.2)$ & $156(21.3)$ \\
Seatbelt & $248(39.2)$ & $253(34.1)$ & $273(37.9)$ & $294(40.3)$ & $281(38.4)$ \\
Both & 20 & 22 & 29 & 43 & 33 \\
Seating position & & & & & \\
Front seated & $35(5.5)$ & $55(7.4)$ & $27(3.7)$ & $30(4.1)$ & $53(7.3)$ \\
Rear seated & $459(72.6)$ & $495(66.6)$ & $475(65.9)$ & $472(64.7)$ & $547(74.8)$ \\
Adult's lap & $40(6.3)$ & $91(12.2)$ & $72(10.0)$ & $85(11.7)$ & $70(9.6)$ \\
Others & $92(14.6)$ & $67(9.0)$ & $112(15.5)$ & $87(11.9)$ & $49(6.7)$ \\
\hline
\end{tabular}

a Less than the total because of missing value.

Table 3. Factors associated with child safety traveling in a car.

\begin{tabular}{|c|c|c|c|}
\hline & \multirow{2}{*}{$\mathrm{N}(3556)$} & \multicolumn{2}{|c|}{ RR (95\% CI) } \\
\hline & & Properly rear seated & Use car seat or seatbelt \\
\hline \multicolumn{4}{|l|}{ Age (years) } \\
\hline$\leq 8$ & 2391 & $0.349(0.294,0.415)^{* *}$ & $0.715(0.616,0.831)^{* *}$ \\
\hline$>9$ & 1165 & Ref & Ref \\
\hline \multicolumn{4}{|l|}{ Gender } \\
\hline Boy & 1712 & $1.088(0.940,1.259)$ & $0.945(0.823,1.086)$ \\
\hline Girl & 1844 & Ref & Ref \\
\hline \multicolumn{4}{|c|}{ Relationship with driver } \\
\hline Parent & 3427 & $0.841(0.569,1.243)$ & $1.303(0.895,1.896)$ \\
\hline Not parent & 129 & Ref & Ref \\
\hline \multicolumn{4}{|c|}{ Driver's education } \\
\hline$\geq$ College & 2245 & $1.318(1.126,1.544)^{* *}$ & $1.024(0.882,1.189)$ \\
\hline$<$ College & 1311 & Ref & Ref \\
\hline \multicolumn{4}{|c|}{$\begin{array}{l}\text { Family income } \\
\text { (RMB/year) }\end{array}$} \\
\hline$\geq 10 \mathrm{w}$ & 2144 & $1.272(1.091,1.483)^{* *}$ & $1.014(0.876,1.173)$ \\
\hline$<10 \mathrm{w}$ & 1412 & Ref & Ref \\
\hline $\begin{array}{c}\text { Understanding } \\
\text { car seat }\end{array}$ & & & \\
\hline
\end{tabular}




\section{Continued}

\begin{tabular}{cccc}
\hline Known & 729 & $1.993(1.633,2.434)^{* *}$ & $4.484(3.659,5.495)^{* *}$ \\
Unknown & 2827 & Ref & Ref \\
$\begin{array}{c}\text { Concern on legislation } \\
\text { of car seat }\end{array}$ & & & \\
Concern & 2373 & $0.915(0.780,1.074)$ & $1.400(1.206,1.625)^{* *}$ \\
Not concern & 1183 & Ref & Ref \\
$\begin{array}{c}\text { Understanding about } \\
\text { recall of defective car } \\
\text { seat }\end{array}$ & & & $1.279(1.065,1.536)^{* *}$ \\
Known & 705 & $0.995(0.824,1.202)$ & Ref \\
Unknown & 2851 & Ref &
\end{tabular}

${ }^{*} 0.01<\mathrm{p}<0.05 ;{ }^{* *} \mathrm{p}<0.01$.

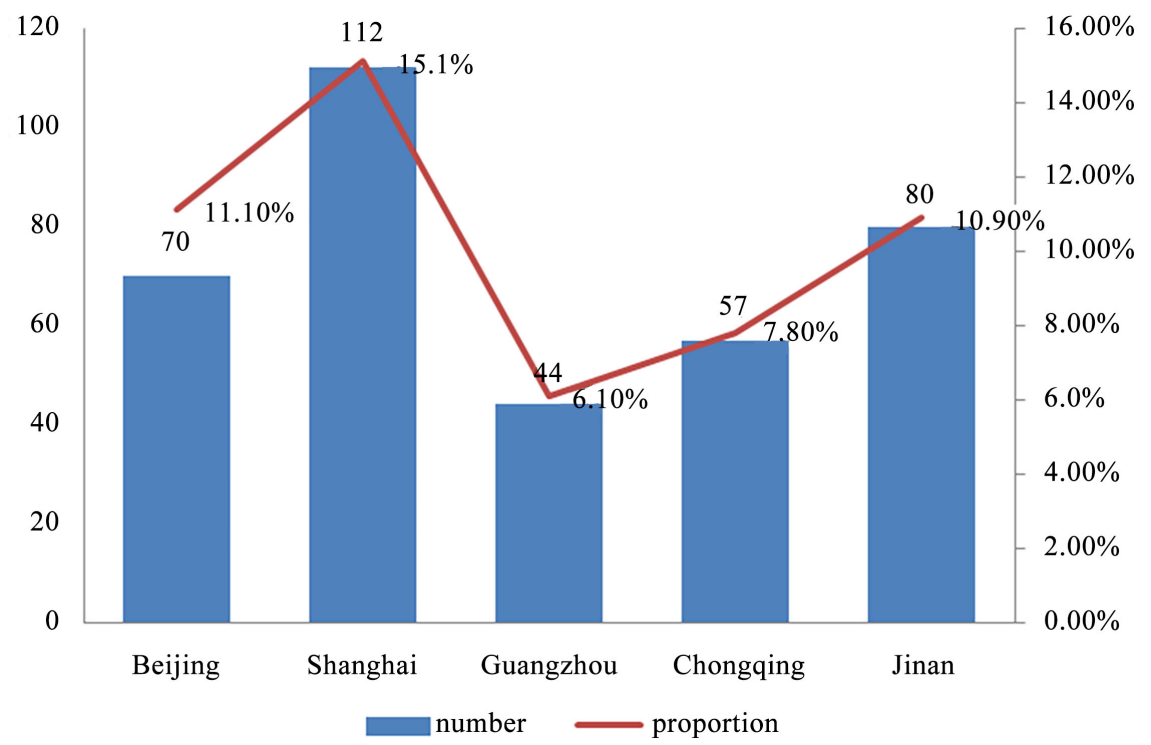

Figure 1. Use car seat on rear seat, number and proportion, in different cities, 2014-2015, $\mathrm{n}(\%)$.

child restraint use and seating practice for child passengers in China by taking appropriate measures and provide some insight into the relevant factors influencing these practices.

\subsection{Prevalence of Rear Seating Alone/Restraint Use}

The prevalence $(68.8 \%)$ of rear seating among child passengers is lower in this study than that (83.1\%) reported among 970 parents surveyed in Shanghai in the period of 2008-2009 [10], whereas the prevalence of restraint use for children (54.7\%) is higher than that (39.2\%) reported among 970 parents surveyed in Shanghai in the period of 2008-2009 [10]; compared with the results of the on-site observation survey in toll stations in Shanghai in June 2009, the prevalence of rear seating among child passengers is higher in this study than that 
(55.9\%) reported in on-site observation [12], and the prevalence of restraint use for children is much higher than that (6.0\%) reported in on-site observation [12]. The different results of above surveys could be partly due to the different ages of children ( 1 - 15 years old versus 3 - 7 years old) and different survey locations (10 early education institutions, 15 kindergartens and 10 primary schools in first-tier cities versus 5 kindergartens in Shanghai), especially the difference in aspect of economic and cultural development in first-tier cities could have a great impact on the analysis results; the difference between questionnaire survey results and on-site observation results could be mainly due to different survey methods, because the data collected from questionnaire is generally better than the actual observed data.

The prevalence of child restraint use (20.9\%) among children in this study is much lower than that seen in developed countries, for example, $86 \%$ in the USA and $90 \%$ in Australia [13] [14]. This difference may be attributed in part to the lack of effective strategies, such as public lectures on the use of child restraints and legislation on compulsory child restraint use. In addition, the misuse of car seat in China was very serious.

\subsection{Factors Influencing Optimal Seating Position}

This study found that younger children (aged $\leq 8$ years) were less likely to be always rear seated, which is opposite to the trend in Australia and in European countries [15] [16]. This difference may be explained by the higher use of child restraints among younger children in Australia and in European countries, which require to be installed on rear seat. Meanwhile, other cultural differences may play a role in this difference between these countries. For example, Chinese parents are used to place their children beside them in the front when driving. This study also found that drivers with higher education level is favorable for children rear sitting, which is consistent with the results of the study on child safety conducted in Shanghai [10]. The higher the driver education level is, the more likely to place the child passengers on rear seat when driving is. In addition, this study also found that the higher the family income and the better understanding about child restraints are advantages of sitting children on rear seats. Therefore, this finding may imply that lectures for child restraint use are helpful to improve the prevalence of rear sitting among child passengers.

\subsection{Factors Influencing Restraint Use}

This study found that younger children were less likely to use child restraints, which is consistent with the results of the study on child safety conducted in Shantou [11]. This difference is mainly related to Chinese traditional culture. Chinese parents are more likely to place children on their laps during driving and mistakenly believe that it is a good way to protect children. The more understanding about car seat, the more concern on the legislation of car seat and the more understanding about recall of defective car seat by drivers, the more 
likely for children to be restrained during travel. This finding also implies that enhanced parental knowledge for safe car traffic may improve the safety of child passenger. It is necessary to understand the reasons for less restraint use before compulsory measures are taken to use child restraint. This survey found that most parents claimed that the price of child restraint in current Chinese market was much higher and some parents did not pay attention to information on car seat legislation. Therefore, it implies that price and government intervention have a great impact on the improvement of child restraint use.

\subsection{Implications}

In the absence of legislation mandating child restraint use among children and because of less public lectures about child restraint use and optimal sitting position, educational lectures on child travel safety may be organized to face the current situation in Chinese first-tier cities and improve child safety during travel. Moreover, the government needs to take a mandatory intervention in case of not using child restraints during travel [17].

In addition to targeting deficiencies in knowledge about child restraints among most of parents, efforts to improve child passenger safety shall be considered, such as regular release of information about child travel safety on the national authority's websites and improvement of prevalence of child restraint use. In addition, installation requirements for child restraints should be taken into consideration during vehicle design. During this period of rapid motorization in China, appropriate measures are taken to improve child travel safety and it is necessary to define the institutions or departments for specific implementation of relevant measures at the same time. For example, regular release of information about child restraints, relevant legislation information and the recall information of defective child restraint product can enhance the parents' knowledge about child travel safety in cars. Meanwhile, other measures such as price cut on child restraints also have a great impact on improving child restraint use [18] [19]. Due to the huge difference between booming motor vehicle ownership in the city and rare safety interventions in road traffic management, this study has important implications for car seat interventions.

\subsection{Limitations}

This survey summarizes the current condition of child travel safety in five cities to explore the factors influencing child passenger safety practices. However, the selected samples are only representative of the first-tier cities in China, rather than most of the second-tier and third-tier cities. At the same time, the representativeness of the surveyed locations randomly selected remains also to be discussed. In addition, the questionnaire does not cover some conditions such as whether driver was wearing seat belt and how many passengers were sitting in the car, which may affect the child travel safety. The studies showed that the survey data is always superior to the data obtained in on-site observation, especially 
when the surveyed parents agreed with the necessity of using child restraints; therefore, the questionnaire survey results often lead to overestimation of child restraint use [17]. Although the results obtained in on-site observation are more authentic, the questionnaire survey results may also reflect the attitude towards children safety practices. The results of this study are important for promoting children travel safety legislation and educational lectures related to child safety practices.

\section{Conclusion}

By describing the low utilization of child restraint system (20.9\%) and common suboptimal of child seating position (31.2\%) in China, this study sets out the case for urgent attention to child passenger safety as well as supports the development and implementation of child passenger safety regulations and education programs in China.

\section{References}

[1] World Health Organization (2013) WHO Global Status Report on Road Safety 2013: Supporting a Decade of Action. World Health Organization, Geneva.

[2] Traffic Management Bureau of the Ministry of Public Security (2013) Annual Report of People's Republic of Traffic and Road Accident Statistics. Traffic Management Research Institute of the Ministry of Public Security, Wuxi. (In Chinese)

[3] Zhang, X., Xiang, H., Jing, R. and Tu, Z. (2011) Road Traffic Injuries in the People's Republic of China, 1951-2008. Traffic Injury Prevention, 12, 614-620. https://doi.org/10.1080/15389588.2011.609925

[4] Huang, Y.H., Zhang, W., Murphy, L., Shi, G. and Lin, Y. (2011) Attitudes and Behavior of Chinese Drivers Regarding Seatbelt Use. Accident Analysis \& Prevention, 43, 889-897. https://doi.org/10.1016/j.aap.2010.11.009

[5] Durbin, D.R., Chen, I., Smith, R., et al. (2005) Effects of Seating Position and Appropriate Restraint Use on the Risk of Injury to Children in Motor Vehicle Crashes. Pediatrics, 115, 305-309. https://doi.org/10.1542/peds.2004-1522

[6] Zhu, B., Zhu, X. and Miao, Q. (2009) Present and Future Challenges of Child Passenger Safety. Automobile \& Parts, 5, 28-31.

[7] Huang, Y.H., Zhang, W., Murphy, L., Shi, G. and Lin, Y. (2011) Attitudes and Behavior of Chinese Drivers Regarding Seatbelt Use. Accident Analysis \& Prevention, 43, 889-897. https://doi.org/10.1016/j.aap.2010.11.009

[8] Routley, V., Ozanne-Smith, J., Li, D., et al. (2008) China Belting up or Down? Seat Belt Wearing Trends in Nanjing and Zhoushan. Accident Analysis \& Prevention, 40, 1850-1858. https://doi.org/10.1016/j.aap.2008.08.007

[9] Purc-Stephenson, R.J., Ren, J. and Snowdon, A.W. (2010) An Exploratory Study of Parents' Use and Knowledge of Car Safety Seats in Beijing, China. International Journal of Injury Control and Safety Promotion, 17, 231-238.

[10] Pan, S., Du, W., Jiang, F., et al. (2012) Exploring Child Car Passenger Safety Practices in China: Experience from a Parental Survey in Shanghai. Injury Prevention, 18, 133-137. https://doi.org/10.1136/injuryprev-2011-040049

[11] Chen, X.J., Yang, J.Z., Peek-Asa, C., McGehee, D.V. and Li, L.P. (2014) Parents' Knowledge, Attitude, and Use of Child Restraints, Shantou, China. American Journal of Preventive Medicine, 46, 85-88. https://doi.org/10.1016/j.amepre.2013.08.017 
[12] Pan, S., Du, W., Jiang, F., et al. (2011) Restraint Use and Seating Position among Child Car Passengers: An Observational Study in Shanghai. Accident Analysis \& Prevention, 43, 2195-2199. https://doi.org/10.1016/j.aap.2011.06.014

[13] Peden, M., Scurfield, R., Sleet, D., et al. (2004) World Report on Road Traffic Injury Prevention. World Health Organization, Geneva.

[14] Glassbrenner, D. and Ye, T. (2008) Child Restraint Use in 2007 Duse of Correct Restraint Type. National Center for Statistics and Analysis, National Highway Traffic Safety Administration (NHTSA). US Department of Transportation, Washington DC.

[15] Lennon, A. (2007) A Risky Treat: Exploring Parental Perceptions of the Barriers to Seating Their Children in the Rear Seats of Passenger Vehicles. Injury Prevention, 13, 105-109.

[16] Segui-Gomez, M., Glass, R. and Graham, J.D. (1998) Where Children Sit in Motor Vehicles: A Comparison of Selected European and American Cities. Injury Prevention, 4, 98-102.

[17] Du, W., Finch, C., Hayen, A., et al. (2010) Relative Benefits of Population-Level Interventions Targeting Specific Restraint Use Behaviours in Child Car Passengers. Pediatrics, 125, 304-312.

[18] Erkoboni, D., Ozanne-Smith, J., Rouxiang, C. and Winston, F.K. (2010) Cultural Translation: Acceptability and Efficacy of a U.S.-Based Injury Prevention Intervention in China. Injury Prevention, 16, 296-301. https://doi.org/10.1136/ip.2009.023341

[19] Macy, M.L., Clark, S.J., Freed, G.L., et al. (2012) Carpooling and Booster Seats: A National Survey of Parents. Pediatrics, 129, 290-298.

https://doi.org/10.1542/peds.2011-0575 